\title{
A Note on the Release of Available Potential Energy
}

\author{
Tsing-Chang Chen and Anthony R. Hansen
}

Department of Earth Sciences, Iowa State University, Ames, Iowa 50011, U.S.A.

\section{Joseph J. Tribbia}

National Center for Atmospheric Research, Boulder, Colorado 80803, U.S.A. (Manuscript received 10 November 1980, in revised form 26 January 1981)

\begin{abstract}
The height and temperature fields at the mandatory levels during a two-month period (December 1977-January 1978) are used to evaluate the conversion between available potential energy $(A)$ and kinetic energy $(K), C(A, K)$. The results reveal:

1. The energy conversion due to the mean meridional circulation, $C\left(A_{Z}, K_{Z}\right)=-0.18 \mathrm{Wm}^{-2}$, and due to the eddy motions, $C\left(A_{E}, K_{E}\right)=2.6 \mathrm{Wm}^{-2}$.

2. $C\left(A_{Z}, K_{Z}\right)$ is attributed to the standing (2-month mean) mode, while $C\left(A_{E}, K_{E}\right)$ is due to the transient eddies.

3. The contributions to $C\left(A_{E}, K_{E}\right)$ from various wave number regimes, long waves $(n=1-4)$, and cyclone and short waves $(n=5-15)$, are:

a. Transient cyclone and short waves are dominant in the mid-latitudes and the middle layer of atmosphere.

b. Transient long waves are significant in the middle layer of the atmosphere at midand high latitudes.

c. Standing long waves are not negligible in the mid-latitudes and the middle layer of atmosphere.
\end{abstract}

\section{Introduction}

The conversion between available potential energy $(A)$ and kinetic energy $(K), C(A, K)$, is regarded as the baroclinic process that maintains the atmospheric circulation (Wiin-Nielsen, 1968). Tomatsu (1979) recently made an extensive computation of this energy conversion employing multilevel data. However, he has noted that there had been very few analyses of $C(A, K)$ for the hemisphere. This might well be due to the difficulty of evaluating the $\omega$ field in the atmosphere.

Recently, we used an alternative mathematical algorithm to solve the $\omega$ equation (see Apendix) rather than the conventional relaxation method. Some interesting features of $C(A, K)$ were found in our computations using a two-month (December 1977-January 1978) multilevel data set analyzed at the National Meteorological Center (NMC). The purpose of this note is to report these $C(A, K)$ results in the wave number regime and the contributions to $C(A, K)$ from the standing and transient modes of the atmospheric motion.

\section{Computation and Data}

The conversion between $A$ and $K$,

$$
C(A, K)=\frac{1}{g} \int_{0}^{p_{0}} \int_{S}-\frac{R}{p} \omega T d s d p,
$$

can be expressed in terms of a Fourier expansion representing the contribution from various wave components.

$$
\begin{gathered}
C(A, K)=\int_{0}^{p_{0}} \int_{\phi}-\frac{R}{p} \omega_{0} T_{0} \cos \phi d \phi d p+\frac{1}{g} \int_{0}^{p_{0}} \int_{\phi} \sum_{n=1}^{N}-\frac{R}{p}\left(\omega_{n} T_{n} *+\omega_{n} * T_{n}\right) \cos \phi c \phi d p \\
C(0) \\
\sum_{n=1}^{N} C(n) \\
C\left(A_{Z}, K_{Z}\right)
\end{gathered}
$$


The notations used are conventional and ()$^{*}=$ complex conjugate of ( ). The two terms on the right-hand side of (1) are the energy conversions due to the mean meridional and eddy motions, respectively.

The expression of $C(A, K)$ can also be resolved further to examine the contributions from the standing and transient modes of the atmospheric circulation.

$$
\begin{aligned}
& \overline{C(A, K)}=\frac{1}{g} \int_{0}^{p_{0}} \int_{\phi}-\frac{R}{p} \bar{\omega}_{0} \bar{T}_{0} \cos \phi d \phi d p+\frac{1}{g} \int_{0}^{p_{0}} \int_{\phi}-\frac{R}{p} \overline{\omega_{0}^{\prime} T_{0}^{\prime}} \cos \phi d \phi d p \\
& C(0)_{\mathrm{S}} \\
& C(0)_{T} \\
& C\left(A_{Z}, K_{Z}\right)_{S} \\
& C\left(A_{Z}, K_{Z}\right)_{T} \\
& +\frac{1}{g} \int_{0}^{p_{0}} \sum_{n=1}^{N}-\frac{R}{p}\left(\bar{\omega}_{n} \bar{T}_{n} *+\bar{\omega}_{n} * \bar{T}_{n}\right) \cos \phi d \phi d p+\frac{1}{g} \int_{0}^{p_{0}} \int_{\phi} \sum_{n=1}^{N}-\frac{R}{p}\left(\overline{\left(\omega_{n}^{\prime} T_{n}{ }^{\prime *}\right.}+\overline{\omega_{n}{ }^{\prime *} T_{n}{ }^{\prime}}\right) \cos \phi d \phi d p \\
& \sum_{n=1}^{N} C(n)_{S} \\
& C\left(A_{E}, K_{E}\right)_{S} \\
& \sum_{n=1}^{N} C(n)_{T} \\
& C\left(A_{E}, K_{E}\right)_{T}
\end{aligned}
$$

where $(\bar{\square})=$ time mean and ()$^{\prime}=(\quad)-(\overline{)}$, is the transient mode. The subscripts $S$ and $T$ denote the standing transient modes, respectively. $N=15$ and the time mean is a two-month average in this study.

The $p$ vertical motion of the atmosphere is evaluated by using the $\omega$ equation of the quasigeostrophic model. The $\omega$ equation has the form of Poisson's equation and conventionally is solved by the relaxation method (e.g., Krishnamurti, 1968). In this study, an alternative approach employing the technique of spherical harmonics to solve the $\omega$ equation is used. The $\omega$ field can be obtained through a matrix equation which relates the spectral coefficients of $\omega$ and the forcing functions in the $\omega$ equation. Our experience reveals that this approach is computationally faster than the conventional relaxation method. The detailed algorithm of this approach is shown in the Appendix. The boundary conditions used in this study are $\omega=0$ at 1,000 and $100 \mathrm{mb}$ for the simplicity of computations.

The computations of this study use the twice daily height and temperature fields on the $2.5^{\circ} \times$ $2.5^{\circ}$ grid of the NMC analysis for December 1977 and January 1978. The data are at the mandatory levels; $1,000,850,700,500,400,300,250$, 200,150 , and $100 \mathrm{mb}$. The domain of integration in (1) and (2) is from $20^{\circ} \mathrm{N}$ to $85^{\circ} \mathrm{N}$ and from $1,000 \mathrm{mb}$ to $100 \mathrm{mb}$.

\section{Results}

An overall view of the conversion between available potential energy and kinetic energy for various modes of the atmospheric motion is provided in Table 1. Note that the eddy conversion is also divided into two groups: $\sum_{n=1}^{4} C(n)$ repre- sents the long-wave regime and $\sum_{n=5}^{15} C(n)$ the cyclone and short-wave regime. The numerical values of $C\left(A_{Z}, K_{Z}\right)=-0.18 \mathrm{Wm}^{-2}$ and $C\left(A_{E}\right.$,

Table 1. Contributions to conversion between available potential energy $(A)$ and kinetic euergy $(K)$ from various modes of atomospheric motions. Unit: $\mathrm{Wm}^{-2}$.

\begin{tabular}{lccc}
\hline & $\begin{array}{c}\text { Total } \\
(S+T)\end{array}$ & $\begin{array}{c}\text { Standing } \\
(S)\end{array}$ & $\begin{array}{c}\text { Transient } \\
(T)\end{array}$ \\
\hline$C\left(A_{Z}, K_{Z}\right)$ & -8.18 & -0.22 & 0.04 \\
$C\left(A_{E}, K_{E}\right)$ & 2.60 & 0.40 & 2.20 \\
$\sum_{n=1}^{4} C(n)$ & 1.15 & 0.36 & 0.79 \\
$\sum_{n=5}^{15} C(n)$ & 1.45 & 0.04 & 1.41 \\
\hline
\end{tabular}

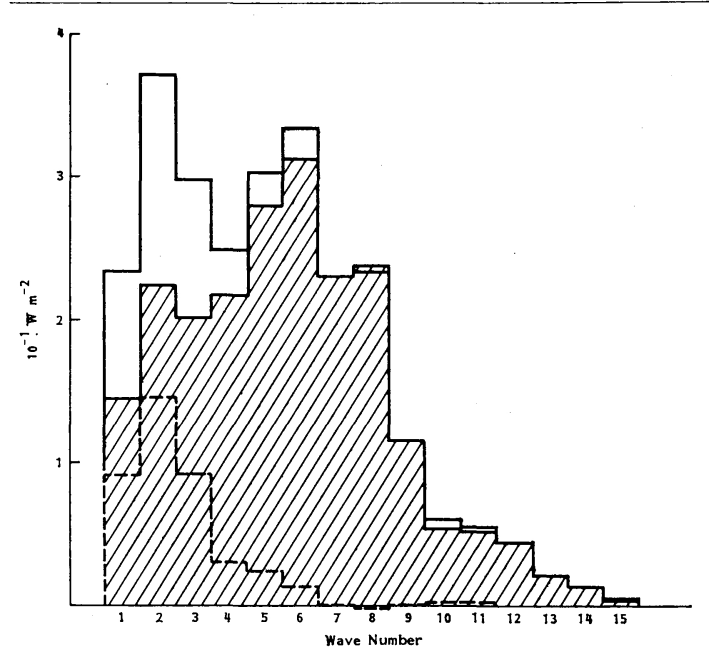

Fig. 1 Spectral distributions of $C(n)$ (solid line), $C(n)_{T}$ (solid line enclosing the hatched area) and $C(n)_{S}$ (dashed line). Unit: $10^{-1} \mathrm{Wm}^{-2}$. 
$\left.K_{E}\right)=2.6 \mathrm{Wm}^{-2}$ in the present study. Tomatsu $C\left(A_{E}, K_{E}\right)=3.14 \mathrm{Wm}^{-2}$. Our results are someobtains a two-month (December and January) what smaller than Tomatsu's, but not unrealistic. mean values of $C\left(A_{Z}, K_{Z}\right)=-0.6 \mathrm{Wm}^{-2}$ and In fact, our results are also close to Oerlemans'
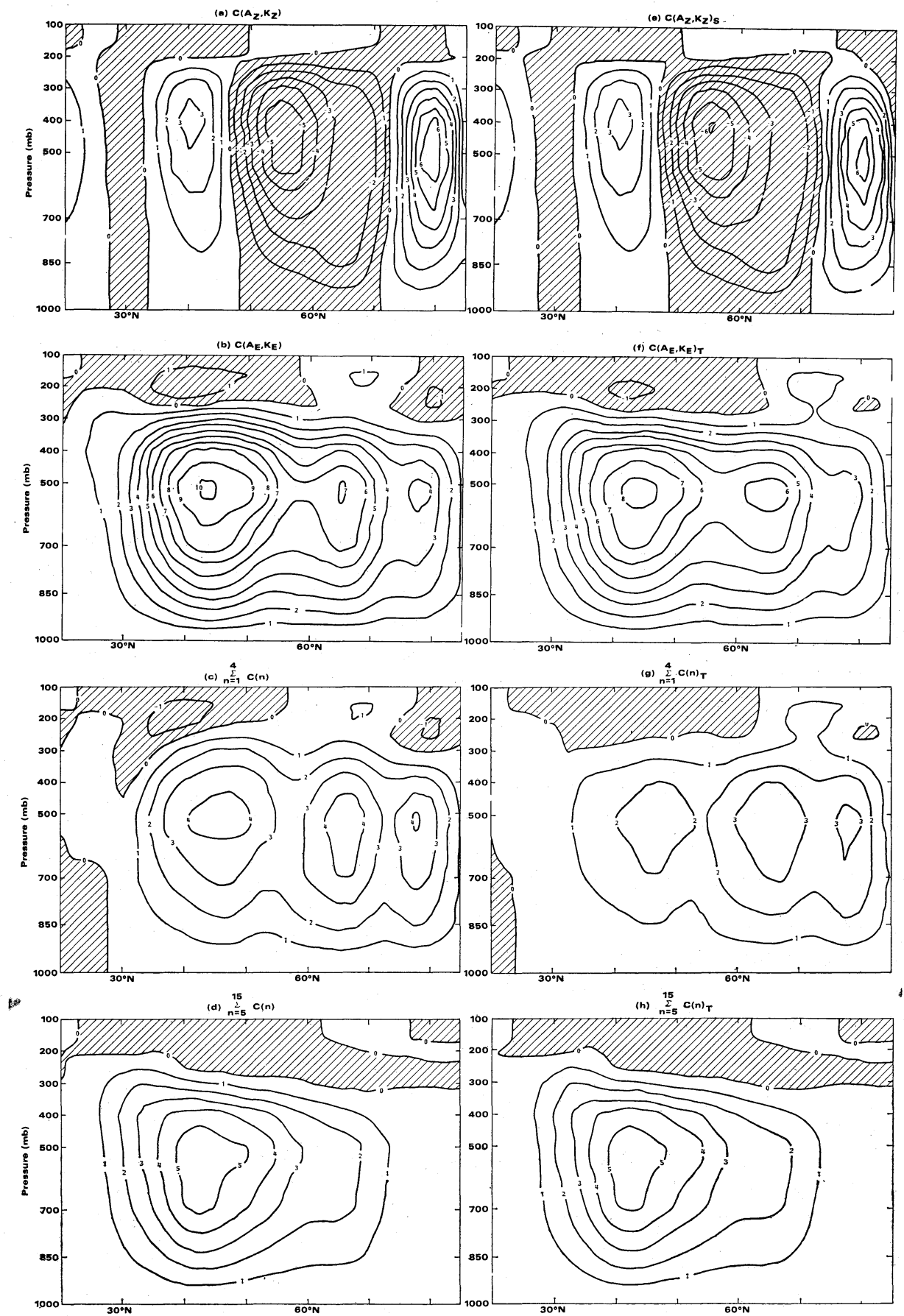

Fig. 2 Latitudial-height distribution of (a) $C\left(A_{Z}, K_{Z}\right)$, (b) $C\left(A_{E}, K_{E}\right)$ (c) $\sum_{n=1}^{4} C(n)$, (d) $\sum_{n=2}^{15} C(n)$, (e) $C\left(A_{Z}, K_{Z}\right)_{s}$, (f) $C\left(A_{E}, K_{E}\right)_{T},(\mathrm{~g}) \sum_{n=1}^{4} C(n)_{T}$ and (h) $\sum_{n=5}^{15} C(n)_{T}$, Unit : $10^{-3} \mathrm{Wm}^{-2} \mathrm{mb}^{-1}$, 
(1980) recent estimate of $C\left(A_{E}, K_{E}\right)$ which is $2.1 \overline{\mathrm{W}} \mathrm{m}^{-2}$ in winter. The salient features shown in Table 1 are; (1) $\sum_{n=1}^{4} C(n)$ and $\sum_{n=1}^{15} C(n)$ are comparable; (2) $C\left(A_{Z}, K_{Z}\right)$ is attributed to the standing mode and $C\left(A_{E}, K_{E}\right)$ is mainly contributed by the transient eddies; (3) the major amount of $\sum_{n=1}^{4} C(n)$ is due to the transient eddies, but the contribution from the standing eddies is not insignificant, and; (4) $\sum_{n=5}^{15} C(n)$ is mainly provided by the transient eddies.

The spectral distribution of $C(n)$ is shown in Figure 1. The maximum values $C(n)$ in this study appear at wave number 2 and 6 . This is in agreement with the spectral energetics results compiled by Saltzman (1970). Tomatsu's computation shows that the maximum $C(n)$ occurs at waves 1 and 3 in winter. The hatched area of Figure 1 represents the spectrum of $C(n)_{T}$. The maximum value of $C(n)_{T}$ occurs at wave 6 . The contribution of $C(n)_{S}$ comes from waves 1-3.

In order to have a better view of the climato$\operatorname{logy}$ of the conversion between $A$ and $K$, Figure 2 displays the latitudinal height distribution of the energy conversion for various modes of atmospheric motions and various wave number regimes. The distribution of $C\left(A_{\mathrm{Z}}, K_{\mathrm{Z}}\right)$, Figure $2 \mathrm{a}$, is similar to that shown in Tomatsu's study. The negative values appear between $50^{\circ} \mathrm{N}$ and $70^{\circ} \mathrm{N}$ which may be the result of the Ferrel circulation. The positive values occur between $35^{\circ} \mathrm{N}$ and $50^{\circ} \mathrm{N}$, and in the polar area, north of $70^{\circ} \mathrm{N}$. Although the areal average of $C\left(A_{Z}, K_{Z}\right)$ is smaller in this study, the numerical values in the $C\left(A_{z}\right.$, $K_{Z}$ ) distribution in the current study are larger than Tomatsu's. This indicates that the intensity of the mean meridional circulation in the winter analyzed in this study is stronger.

The distribution of $C\left(A_{E}, K_{E}\right)$, Figure $2 \mathrm{~b}$, shows three areas of maximum value of $500 \mathrm{mb}$ : $45^{\circ} \mathrm{N}$ (major one), $65^{\circ} \mathrm{N}$ and $75^{\circ} \mathrm{N}$. Tomatsu's result only shows a maximum value at $600 \mathrm{mb}$ and $50^{\circ} \mathrm{N}$. It is of interest to examine the contribution of different wave regimes to $C\left(A_{E}, K_{E}\right)$. The comparison between $C\left(A_{E}, K_{E}\right), \sum_{n=1}^{4} C(n)$ (Figure 2c) and $\sum_{n=1}^{15} C(n)$ (Figure 2d) shows very clearly that the major maximum of $C\left(A_{E}, K_{E}\right)$ at $45^{\circ} \mathrm{N}$ is mainly attributed to the cyclone and short waves. The two minor maxima of $C\left(A_{E}\right.$,
$K_{E}$ ) at $65^{\circ} \mathrm{N}$ and $75^{\circ} \mathrm{N}$ are due to the long waves. This may indicate that the wave activities in the high latitudes are dominated by the long waves, while in the mid-latitudes cyclone and short waves are active, in addition to the long waves.

In the right-hand column of Figure 2, we display the latitude-height distributions of either the standing or transient modes of those four quantities discussed above depending upon which provides the dominant contribution to their totals, respectively. The $C\left(A_{Z}, K_{Z}\right)$ distribution is more or less decided by $C\left(A_{Z}, K_{Z}\right)_{S}$, while the $C\left(A_{E}\right.$, $K_{E}$ ) distribution is determined by $C\left(A_{E}, K_{E}\right)_{T}$. The further breakdown of $C\left(A_{E}, K_{E}\right)_{T}$ into $\sum_{n=1}^{4} C(n)_{T}$ and $\sum_{n=5}^{15} C(n)_{T}$ shows that $\sum_{n=5}^{15} C(n)$ distribution is almost identical to $\sum_{n=1}^{15} C(n)_{T}$. However, $\sum_{n=1}^{4} C(n)$ and $\sum_{n=1}^{4} C(n)_{T}$ has some significant difference over the location where the maximum value of $C\left(A_{E}, K_{E}\right)$ occurs, i.e. $500 \mathrm{mb}$ and $45^{\circ} \mathrm{N}$. The difference between these two quantities indicates that the major contribution of the standing eddies appears at $500 \mathrm{mb}$ and $45^{\circ} \mathrm{N}$.

The idea of computing the energy conversion between $A$ and $K$ is not new. However, very few studies have been made to evaluate this energy conversion using multilevel observational data. Some interesting features shown in our $C(A, K)$ computations may be useful in evaluating model simulations of the atmospheric general circulation.

\section{Acknowledgement}

This study is supported in part by the NSF grant ATM-7915800 and the NASA grant NSG5339.

\section{Appendix}

The of equation of the quasi-geostrophic model may be written as

$$
\nabla^{2} \omega+\frac{f^{2}}{\sigma} \frac{\partial^{2} \omega}{\partial p^{2}}=F,
$$

where

$$
F=\frac{f}{\sigma} \frac{\partial}{\partial p} J(\psi, \zeta+f)+\frac{1}{\sigma} \nabla^{2} J\left(\phi, \frac{\partial \Phi}{\partial p}\right) .
$$

$\sigma=\sigma(p)$ and $\Phi$ is geoptential. The forcing of function in (A1) contains only the vertical differentiation of vorticity advection and the Laplacian of thermal advection. Let us express $\omega$ and $F$ in terms of solid spherical harmonics (Platzman, 
1960).

$$
\omega=\sum_{m} \sum_{n} \omega_{n}{ }^{m} Y_{n}{ }^{m}
$$

and

$$
F=\sum_{m} \sum_{n} F_{n}{ }^{m} Y_{n}{ }^{m}
$$

where $\boldsymbol{Y}_{n}^{m}=\boldsymbol{P}_{n}{ }^{m} \boldsymbol{e}^{i m \lambda}$ and $\boldsymbol{P}_{n}^{m}(\mu)$ is the Associated Legendre function of the latitude, $\phi$, at which $\mu=\sin \phi . \quad \omega_{n}{ }^{m}$ and $F_{n}{ }^{m}$ are the spectral coefficients of $\omega$ and the forcing function, respectively. Substitution (A2) and (A3) into (A4), we can obtain the spectral form of (A2),

$$
-\frac{n(n+1)}{a^{2}} \omega_{n}^{m}+\frac{f^{2}}{\sigma} \frac{\partial^{2} \omega_{n}^{m}}{\partial p^{2}}=F_{n}{ }^{m}
$$

where $a$ is the earth's radius. The second-order derivative of $\omega_{n}{ }^{m}$ in (A4) is evaluated by the finite difference scheme illustrated in Figure A1. The second-order derivative of $\omega_{n}{ }^{m}$ at the level $K$ is evaluated by dividing the difference between the first-order derivative of $\omega_{n}{ }^{m}$ in the middle of levels $(K+1, K)$ and of levels $(K, K-1)$ by $1 / 2\left(\Delta p_{K}+\Delta p_{K+1}\right)$. Therefore, (A4) can be written as,

$$
\begin{aligned}
& A_{K+1} \omega_{n}^{m}(K+1)-B_{K} \omega_{n}^{m}(K) \\
& \quad+C_{K_{-1}} \omega_{n}^{m}(K-1)=F_{n}^{m}(K)
\end{aligned}
$$

where

$$
\begin{aligned}
& A_{K+1}=\frac{2 f^{2}}{\sigma \Delta p_{K+1}\left(\Delta p_{K+1}+\Delta p_{K}\right)} \\
& B_{K}=\frac{n(n+1)}{a^{2}}+\frac{2 f^{2}}{\sigma \Delta p_{K} \Delta p_{K_{+1}}} \\
& C_{K-1}=\frac{2 f^{2}}{\sigma \Delta p_{K}\left(\Delta p_{K+1}+\Delta p_{K}\right)} .
\end{aligned}
$$

Applying (A5) to every level, we can obtain a linear system which can be expressed in terms of a matrix equation,

$$
\bar{M} \bar{\omega}=\bar{F},
$$

where

$$
\begin{aligned}
& \bar{M}=\left[\begin{array}{ccccc}
-B_{1} & A_{2} & 0 & \ldots \ldots \ldots \ldots . & 0 \\
C_{1} & -B_{2} & 0 & \ldots \ldots \ldots \ldots . & 0 \\
\cdot & \cdot & \cdot & & \cdot \\
\cdot & \cdot & \cdot & & \cdot \\
\cdot & \cdot & \cdots & A_{N} \\
0 & 0 & \cdot & C_{N-1} & -B_{N}
\end{array}\right], \\
& \bar{\omega}=\left[\begin{array}{c}
\omega_{n}^{m}(1) \\
\omega_{n}^{m}(2) \\
\cdot \\
\cdot \\
\omega_{n}^{m}(N)
\end{array}\right] \text { and } \quad \bar{F}=\left[\begin{array}{c}
F_{n}^{m}(1) \\
F_{n}^{m}(2) \\
\cdot \\
\cdot \\
F_{n}^{m}(N)
\end{array}\right] .
\end{aligned}
$$

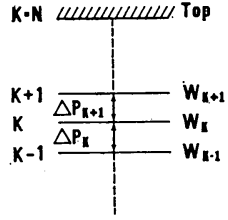

K.1 /7ायोगाया sfe

Fig. A-1 Schematic diagram for the computation of the vertical derivative for $\omega_{n}{ }^{m}$.

$N$ is the maximum number of vertical levels, $\bar{M}$ is a triadiagonal square matrix and $\omega_{n}{ }^{m}$ at the various levels can be obtained by solving (A6).

The procedures are as follows: (a) calculate the forcing function of the $\omega$ equation on the $2.5^{\circ} \times 2.5^{\circ}$ grid; (b) use Ellsaesser's (1966) scheme to create the spectral coefficients of the forcing functions; (c) the spectral coefficients of the vertical motion are solved by equation (A6); and (d) the $\omega$ field is constructed by equation (A2).

The spectral truncation used in this study is triangular with $0 \leq|m| \leq 25$ and $0 \leq n \leq 25$. Since only hemispherical data is available, we must make some assumption concerning the parity at the physical variables. We assume that $\omega$ and $F$ are even.

\section{References}

Ellsaesser, H.W., 1966: Expansion of hemispheric meteorological data in antisymmetric surface spherical harmonic (Laplace) series. J. Appl. Meteor. 5, 263-276.

Krishnamurti, T. N., 1968: A diagnostic balance model for studies of weather systems of low and high latitudes, Rossby number less than 1. Mon. Wea. Rev., 96, 197-207.

Oerlemans, J., 1980: An observational study of the upward sensible heat flux by synoptic-scale transients. Tellus, 32, 6-14.

Platzman, G. W., 1960: The spectral form of the vorticity equation. J. Meteor., 17, 635-644.

Saltzman, B., 1970: Large scale atmospheric energetics in the wave number domain. Rev. Geophys. Space Phys., 8, 289-302.

Tomatsu, K., 1979: Spectral energetics of the troposphere and lower stratosphere. Advances in Geophysics, Vol.21, Academic Press, 289-405.

Wiin-Nielsen, A., 1968: On the intensity of the general circulation of the atmosphere. Rev. Geophys., 6, 559-879. 


\section{有効位置エネルギーの変換についてのノート}

\section{Tsing-Chang Chen and Anthony R. Hansen}

Department of Earth Sciences, Iowa State University, U.S.A.

\section{Joseph J. Tribbia}

National Center for Atmospheric Research, U.S.A.

指定気圧面に於ける二ヶ月間（1977年12月～1978年 1 月）の高度場と温度場を使って，有効位置 エネルギー (A) と運動ェネルギー $(K)$ との変換， $C(A, K)$ を求めた。その結果，次の事が明らかになった。

1. 平均子午面循環による变換は, $C\left(A z, K_{Z}\right)=-0.18 \mathrm{Wm}^{-2}$ であり, 擾乱による変換は, $C\left(A_{E}, K_{E}\right)=2.6$ $\mathrm{Wm}^{-2}$ である。

2. $C\left(A z, K_{Z}\right)$ は定常性（2 ケ月平均）のモードに起因しているのに対して, $C\left(A_{E}, K_{E}\right)$ は変動性の擾乱に 因っている。

3. 長波 $(n=1 \sim 4)$, 及び低気圧や短波 $(n=5 \sim 15)$ の $C\left(A_{E}, K_{E}\right)$ への寄与は次のと拈りである。
a. 変動性の低気圧や短波は，中緯度と中層で支配的である。
b. 変動性の長波の影響は，中高緯度の中層で重要である。
c. 停滞性の長波の影響は，中緯度と中層では無視できない。 